Rol es and systens of day cent res: El der l y-case st udy of a moder at el y mount ai nous ar ea i $n$ Japan

\begin{tabular}{|c|c|}
\hline 著者 & N shi no Tat suya \\
\hline $\begin{array}{l}\text { j our nal or } \\
\text { publ i cat } i \text { on } \mathrm{titl} \text { e }\end{array}$ & I nt er nat i onal J our nal of Sust ai nabl e Soci et y \\
\hline vol une & 7 \\
\hline nunber & 1 \\
\hline page $r$ ange & 22- 41 \\
\hline year & $2015-03-01$ \\
\hline URL & ht t p: //hdl . handl e. net /2297/41496 \\
\hline
\end{tabular}




\title{
Roles and systems of day centres: elderly-case study of a moderately mountainous area in Japan
}

\author{
Tatsuya Nishino \\ College of Science and Engineering, \\ School of Environmental Design, \\ Kanazawa University, \\ Kakuma, Kanazawa, 920-1192 Japan \\ Fax: +81-76-234-4649 \\ Email: tan378@se.kanazawa-u.ac.jp
}

\begin{abstract}
The provision of housing for the elderly remains a key issue in every ageing society. In contrast, day centres for the elderly have not been given the same level of attention. However, day centres for the elderly are expected to play a more important role in global ageing populations, since keeping the care-needing elderly living in their own homes with proper care services has become part of the mainstream social care vision. Particularly in the kinds of under-populated and ageing areas that are increasing in ageing countries, the lack of day service provision causes direct inconvenience to elderly residents. Focusing on the case of a moderately mountainous area in Japan, where a care system centred on the public hospital has been established, in this paper the discussion focuses on systems of elderly care and the roles they play, by examining the overall picture of the elderly who use such centres.
\end{abstract}

Keywords: ageing society; underpopulated area; moderately mountainous area; Japan; day centres; the elderly; elderly types; elderly care systems; facility roles; living in their own homes.

Reference to this paper should be made as follows: Nishino, T. (2015) 'Roles and systems of day centres: elderly-case study of a moderately mountainous area in Japan', Int. J. Sustainable Society, Vol. 7, No. 1, pp.22-41.

Biographical notes: Tatsuya Nishino is an Assistant Professor in the School of Environmental Design, College of Science and Engineering at Kanazawa University, Japan. He obtained his $\mathrm{PhD}$ at the University of Tokyo, Japan, in 2005 . His research interest is facility design for the elderly.

\section{Introduction}

This study contributes to the construction of a perspective on systems of day centres for the elderly, by making observations on their roles after examining the overall picture of the elderly, as categorised into three types, who visit such centres in a moderately mountainous area of Japan.

One of the great human success stories in the last few decades has been the marked increase in longevity in many societies across the globe (Dummer et al., 2011). Population ageing transcends the divide between developed and developing countries, because every country hopes to foster independent living and quality of life regardless of 
life expectancy (Brink, 1997). In addition, an increasingly ageing population provides a challenge to ageing countries in terms of meeting the needs of an ageing population and creating a policy environment (Parker and Pant, 2011).

One of the main issues in the ageing society has been the provision of housing for the elderly (Kose, 1997; Katan and Werczberger, 1997). For example, in Denmark, known for its highly developed social care system for the aged, formal care was introduced as an alternative to informal care by families (Gottshalk, 1999). They have developed new attitudes towards old age and new ways of housing and providing services to the elderly since 1980. Moreover, their policy has encouraged the elderly to stay in their own homes as long as possible (Lindstroem, 1997). On the other hand, in the Netherlands, a de-linking system of housing and care has been developed, in order to make elderly people more autonomous and force care providers to be more customer-oriented (Egdom, 1997).

In Asia, most countries will be 'aged societies' by 2050, a phenomenon known as 'Ageing Asia' (Nikkei Newspaper November 28th 2011). However, in Asian countries, the elderly have been, and remain, primarily cared for by their own families (Ara, 1997; Chi and Chow 1997). Previous studies have pointed out the need to change from traditional family support to public care systems (Kim, 1997; Hwang, 1997; Harrison, 1997). Japan, as the most rapidly ageing country in Asia, has been developing its social welfare system since 1989 (Tsuno and Honma, 2009). In 2000, the Japanese social care vision turned towards keeping the care-needing elderly in their own homes with proper formal care services, by introducing 'Kaigo Hoken' (The Long-Term Care Insurance Act). It seems to be following the ageing policies of advanced countries such as Denmark.

In such a situation, day centres for the elderly are expected to play a large part ${ }^{1}$ (Nishino, 2005). However, they have not been the subject of much focus since they are not bases for living. That is, a proper system of day centres is now required. Although Japan followed the 'ageing advanced' countries in its care vision, the Japanese day-centres system can become an example of good practice in the ageing society for the following reasons. One of the characteristics of Japanese care centres is that their use is restricted to only those elderly people who need care services (Nishino, 2007). The elderly who do not need care services go to community centres (Tanaka et al., 2002). On the other hand, in Aarhus in Denmark, for example, there are senior centres where every elderly person can go and receive care services if he/she needs them (Nishino and Nagasawa, 2006). Japanese care services are provided by authorised service providers, such as social welfare corporations, supervised by local governments under the Long-Term Care Insurance Act, whereas on the other hand, in Denmark, the care systems for the elderly are provided as public services funded by the tax payer (Nishino and Nagasawa, 2006). Considering the economic stagnation of Northern Europe caused by the burden of high taxation nowadays, it is worth seeing the Japanese system as a counter-example to discuss sustainable social care systems.

For the planning of day centres for the elderly, our questions are as follows;

1 What kinds of elderly people go to day centres?

2 Following this, what is the role of the day centre?

3 Finally, what kind of system of day centres is appropriate in an ageing and also under-populated area? 
In Japan, some studies that focused on the facility planning of day centres for the elderly have been undertaken. Regarding the first question, there have been studies on the attributes of the elderly who go to day centres (Saito and Matsumoto, 1992; Sato et al., 1996). It would be meaningful to take a second look at these, after the introduction of the Long-Term Care Insurance Act in 2001 and its revision in 2006 in the midst of an increase in the elderly population. However, our study is different from others in seeking to understand all the attributes of the elderly who go to day centres in a specific region. Although we focus on the elderly who use Japanese day centres, there would be almost no difference regarding the attributes of the care-needing elderly internationally. For the second question, there are studies discussing a perspective on the planning of day centres by a group led by Professor Ueno (Miyata et al., 1996; Chida et al., 1996; Tobari et al., 2002). Sugawara (2004) has also discussed this issue. For the third question, about facilities allocation, Nosaka and Yoshikawa (1999) proposed an optimum locating method of day service (DS) in Tama New Town based on future population estimations. Their case study targeted a highly populated area, one of the big 'bed towns' of Tokyo. However, the situation is now much more severe in under-populated and also ageing areas. Furthermore, our study is different from the previous research in that its viewpoint is not a single facility's function, but the functional system of facilities in a particular area. In a previous study of an under-populated and ageing area, Tobari et al. (2001) clarified the structures of the living environments of elderly people in an agricultural and mountainous area from the viewpoint of 'Chien' (community ties). Sugawara (2006) focused on community function and management in an ageing mountainous area. Our study is meaningful as a report of a progressive care system in an under-populated, and also ageing, area.

\section{Research objectives and methodology}

\subsection{Objectives}

To answer the research questions mentioned above, the discussion in this paper focuses on the roles and systems of day centres for the elderly by examining the overall picture of the types of elderly people who go to day centres in the case of a moderately mountainous area in Japan, where a care system centred on the public hospital has been established.

\subsection{Methodology}

The study consists of five main parts. Section 1 covers background, previous studies. Section 2 outlines the research objective and our method. In Section 3 to 5, we conducted a case study. Section 3 outlines the surveyed area and its facilities in the case study.

Section 4 summarises the attributes of the elderly, extracts the types, and considers the role of centres. Finally, Section 5 shows the model of M Town's outpatient care system from the viewpoint of user types and the roles of facilities, and then discusses their effectiveness.

In Section 4, for the first question, it is needed to grasp the attributes of the elderly who come to day care (DC) centres. To measuring the attributes of the elderly, there are three standpoints: 
1 physical condition

2 severity of dementia

3 habitation status.

For examining

1 physical condition, the Katz index (1970) is most major index to judge subjects' physical autonomy, by measuring degree of independency at bathing, dressing, toileting, transferring, continence, and feeding

2 severity of dementia, we adopted 'Index of independency in daily living of the elderly with dementia' by Japanese Ministry of Health, Labor and Welfare (2006), because it is most major index in Japan. In the Index, care requiring levels are categorised into 0 , I or IIa, IIb, IIIa, IIIb, IV, and M

3 habitation status, we use three categories: living with family, living alone only during the daytime, and living alone always (Nishino, 2005).

In this study, we attempt to describe the elderly's attributes by combination of these three standpoints:

1 physical condition

2 severity of dementia

3 habitation status.

After examining the attributes of the elderly who come to DC centres, we can progress to discuss

1 what is the role of the day centre

2 what kind of system of day centres are appropriate in an ageing and also under-populated area in Section 4 and Section 5.

\section{Outlines of case study area and facilities}

\subsection{Method of case study}

In the case study, we focus on following questions.

1 What kinds of elderly people go to day centres?

2 Following this, what is the role of the day centre?

3 Finally, what kind of system of day centres is appropriate in an ageing and also under-populated area?

For it, firstly, we focus on the DC centres in M Town in O City in Hiroshima Prefecture. $\mathrm{M}$ Town was selected as the target area for study for the following reasons: Firstly, $\mathrm{M}$ Town is a comparatively closed area located in a moderately mountainous area about 30 
minutes by car from downtown $\mathrm{O}$ city. (O City was formed by the merger of several towns and villages in March 2005.) Therefore, we could obtain all the data on the attributes of the elderly coming to DS centre and DC centre that do not hide particular users' needs or provide incomplete or potentially biased information. Secondly, M Town has a unique system of day centres in that it consists of an integrated DC centre, where rehabilitation is also provided, and several DC centres for the elderly. The system is based on a centralised public hospital with connections to care facilities. From the time before M Town was founded, officials and health workers have sought to provide comprehensive community care $^{2}$ to the area with a network of health, medical and welfare services centred on the public M-hospital.

Secondly, to examine the attributes of elderly users of day centres, it was deemed appropriate to conduct a questionnaire survey. We collected raw data of the attributes (sex, age, place of residence, date of first visit, days of visits, kinds of services received, primary illness, the degree of care needed, the severity of dementia, ADL, living situation, etc.) of the elderly using these facilities in January 2006, January 2007, and January 2008 using questionnaire surveys and supplemental interviews. (From January 2006 to January 2007, the standards for requiring care were amended due to revisions to the Long-Term Care Insurance Act. Specifically, Required Support 1 and Required Support 2 levels were established, resulting in seven levels including Required Care 1 to 5.) We asked staff members to provide personal data on their elderly users by assigning them a number beforehand, so that we could track changes without knowing the individuals' identities. Also, because M Town does not have an elderly welfare centre or mini DC centre, a salon, as part of a preventive approach to long-term care, is held once a month in a community centre.

Thirdly, our examination proceeded according to the following method. After organising the basic attributes of the subjects, we looked at each subject from three standpoints:

1 physical condition

2 severity of dementia

3 habitation status.

For

1 we measured how physically autonomous the subject was (A/B or C, D, E, F, G, O on the Katz ADL scale)

2 whether he or she was mentally autonomous or had dementia to a level requiring care $(0, \mathrm{I}$ or IIa, IIb, IIIa, IIIb, IV, M in the daily autonomy standard for persons with dementia)

3 whether he or she lived with family or alone.

In our observations for 3), we noticed two patterns for those who lived alone during the daytime: those who lived alone always and those who lived with their families but were alone during the day. For the purpose of this study, we treated both groups as those who lived alone during the daytime. Also, we treated the elderly coming to DC and DS in the same manner, although when necessary we divided them. 


\subsection{Features of $M$ town}

Table 1 provides a summary of M Town at the time of January 2006, 2007, and 2008. For comparison, the national average values (at the time of October 2006) are included. The population of M Town at the end of January 2006 was 8,001, which has been followed by a slight rate decrease. Those aged over 65 numbered 2,452. At 30.65\%, the percentage of elderly people greatly exceeded the national average, and it has since risen even higher. However, the population density of the elderly was $29.55 \mathrm{per} \mathrm{km}^{2}$, which was well below the national average. Therefore it could be said that M Town was a stereotypical elderly under-populated region in a central and mountainous area.

Table 1 Summary of data of M Town ${ }^{3}$

\begin{tabular}{|c|c|c|c|c|}
\hline \multirow[b]{2}{*}{ Date } & \multicolumn{3}{|c|}{ M Town } & \multirow{2}{*}{$\frac{\text { Japanese data }}{\text { Oct. } 2006}$} \\
\hline & Jan. 2006 & Jan. 2007 & Jan. 2008 & \\
\hline Area (square kilometre) & 82.98 & 82.98 & 82.98 & 362,197 \\
\hline Population & 8,001 & 7,968 & 7,907 & $127,769,510$ \\
\hline Those aged over 65 & 2,452 & 2,466 & 2,490 & $26,604,000$ \\
\hline Percentage of Elderly & $30.65 \%$ & $30.95 \%$ & $31.49 \%$ & $20.82 \%$ \\
\hline $\begin{array}{l}\text { Population density of the elderly per } \\
\text { sq. km }\end{array}$ & 29.55 & 29.72 & 30.01 & 73.45 \\
\hline Population of elderly living alone & 194 & 216 & 298 & $3,861,000$ \\
\hline $\begin{array}{l}\text { Rate of elderly living alone relative to } \\
\text { total population }\end{array}$ & $2.42 \%$ & $2.71 \%$ & $3.77 \%$ & $7.88 \%$ \\
\hline $\begin{array}{l}\text { Elderly living alone rate, relative to } \\
\text { elderly population }\end{array}$ & $7.91 \%$ & $8.76 \%$ & $11.97 \%$ & $14.51 \%$ \\
\hline $\begin{array}{l}\text { The number of the elderly going to day } \\
\text { service }\end{array}$ & 94 & 107 & 119 & $1,095,535$ \\
\hline $\begin{array}{l}\text { The number of the elderly going to day } \\
\text { care }\end{array}$ & 109 & 100 & 98 & 452,115 \\
\hline $\begin{array}{l}\text { The percentage who used DS relative to } \\
\text { total elderly }\end{array}$ & $3.83 \%$ & $4.34 \%$ & $4.78 \%$ & $4.12 \%$ \\
\hline $\begin{array}{l}\text { The percentage who used DC relative to } \\
\text { total elderly }\end{array}$ & $4.45 \%$ & $4.06 \%$ & $3.94 \%$ & $1.70 \%$ \\
\hline
\end{tabular}

Next, looking at the rate of elderly people who lived alone compared with the total population, its rate of $7.91 \%$ to $11.97 \%$ was slightly lower than national average. Of the elderly, the percentage who used DS centres was $3.83 \%$ compared with an average of $4.78 \%$, which was roughly the same as the national average of $4.12 \%$. On the other hand, the rate of the elderly using outpatient rehabilitation (DC) was 3.94\% compared to $4.45 \%$ among the general population, which greatly exceeded the national average of $1.70 \%$. We believe that this is because a care system centred on the public M hospital has been established.

From the data above, we can characterise M Town as follows:

1 it is under-populated with elderly people

2 the rate of the elderly who lived alone was comparatively low

3 the rate of the elderly coming to outpatient rehabilitation was high. 
Table 2 DC and DS in M town

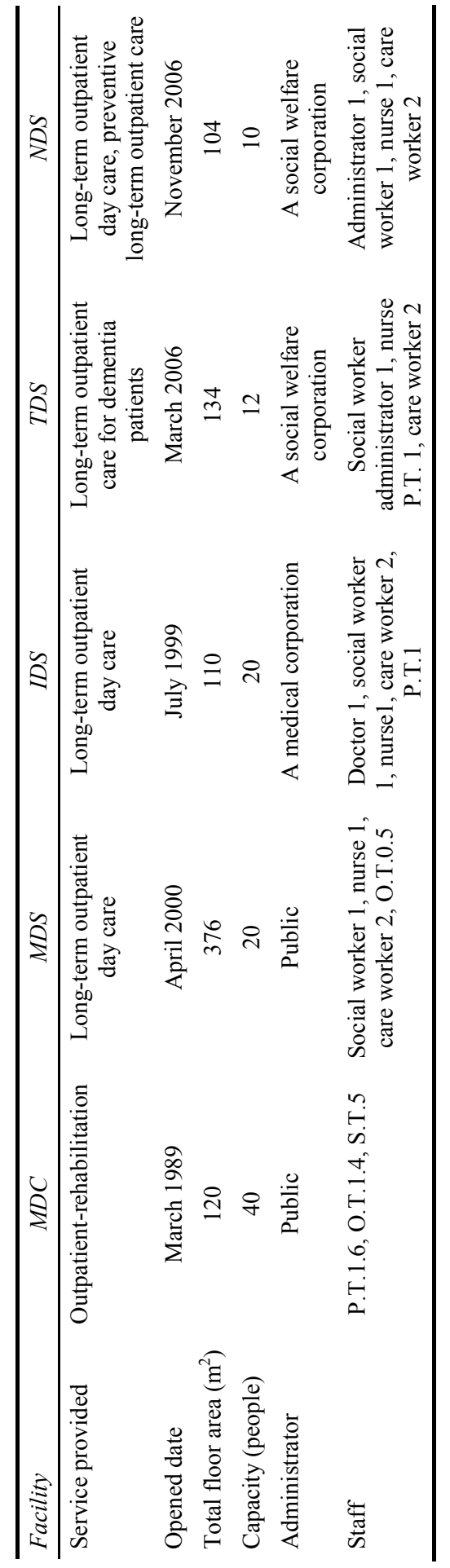


Table 3 Residents' attributes over a period of three years

\begin{tabular}{|c|c|c|c|c|c|c|c|c|}
\hline \multirow{2}{*}{$\frac{\varkappa}{2}$} & in & $\stackrel{n}{\infty}$ & $n$ & $\stackrel{n}{i}$ & 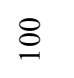 & $\nsubseteq$ & 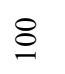 & \\
\hline & $\stackrel{\circ}{\circ}$ & ஆั & $\stackrel{\circ}{\rightarrow}$ & $\stackrel{\leftrightarrow}{\dot{q}}$ & 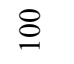 & $\nsubseteq$ & $\stackrel{8}{ }$ & \\
\hline & 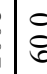 & $\underset{\infty}{\dot{\infty}}$ & $\stackrel{m}{=}$ & $\stackrel{i}{i}$ & $\stackrel{8}{\circ}$ & 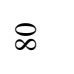 & $\stackrel{8}{ }$ & \\
\hline & 15 & $\underset{+}{+}$ & $\stackrel{n}{+}$ & $\stackrel{m}{3}$ & 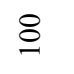 & 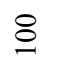 & 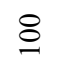 & \\
\hline & 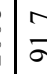 & $\dot{\infty}$ & $\stackrel{\text { aे }}{\text { aे }}$ & ĩ & $\begin{array}{l}\infty \\
\dot{\alpha}\end{array}$ & 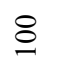 & $\underset{\infty}{m}$ & \\
\hline$\tilde{\imath}$ & $\infty$ & $\vec{\infty}$ & $\stackrel{\infty}{\stackrel{\sim}{\Lambda}}$ & $\vec{i}$ & $\begin{array}{l}\dot{0} \\
\stackrel{\circ}{\circ}\end{array}$ & $\begin{array}{l}\text { 迥 } \\
\stackrel{8}{2}\end{array}$ & kે & \\
\hline & $\infty$ & $\stackrel{\partial}{\dot{\infty}}$ & $\overrightarrow{\vec{i}}$ & i & గूँ & 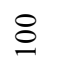 & $\begin{array}{l}n \\
\infty \\
\infty \\
\infty\end{array}$ & \\
\hline & 7 & $\begin{array}{l}n \\
n \\
\infty\end{array}$ & $\hat{\vec{q}}$ & $\cong$ & $\stackrel{\text { ऽ̊ }}{\infty}$ & $\nsubseteq$ & $\begin{array}{l}\stackrel{0}{\dot{b}} \\
\dot{n}\end{array}$ & \\
\hline$\widehat{\imath}$ & $\stackrel{2}{2}$ & $\stackrel{\infty}{\infty}$ & i & $\stackrel{m}{=}$ & $\vec{\sigma}$ & $\stackrel{n}{a}$ & bj & \\
\hline & 苟 & $\underset{\infty}{+\infty}$ & 吕 & $\exists$ & $\stackrel{\Im}{\sigma}$ & $\nsubseteq$ & $\frac{n}{n}$ & \\
\hline & & $\vec{\infty}$ & $\begin{array}{l}\infty \\
\dot{m} \\
m\end{array}$ & $\stackrel{\infty}{-}$ & o.j & $\nsubseteq$ & $\stackrel{\infty}{a}$ & $\nsubseteq$ \\
\hline 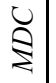 & 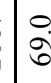 & $\underset{\substack{n \\
\infty \\
\infty}}{p}$ & $\stackrel{\vec{j}}{\text { r }}$ & $\stackrel{g}{=}$ & $\dot{\circ}$ & 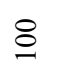 & $\stackrel{\circ}{\circ}$ & 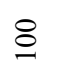 \\
\hline & & $\underset{\infty}{n}$ & 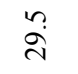 & $\stackrel{g}{9}$ & $\stackrel{\partial}{\dot{\infty}}$ & $\vec{\sigma}$ & $\begin{array}{l}\vec{\infty} \\
\substack{\infty \\
\infty}\end{array}$ & 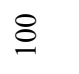 \\
\hline & & 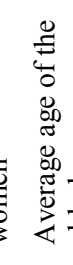 & & & 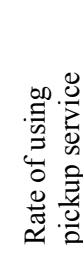 & 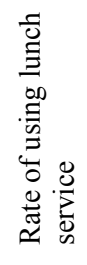 & & \\
\hline
\end{tabular}




\subsection{Outlines of surveyed facilities}

The objects of study were all DS and DC facilities in M Town (see Table 2). At the end of January, 2006, there were three DS and DC facilities in M Town: a DC centre attached to M hospital (hereafter referred to as MDC), a DS centre also attached to M hospital (MDS) - both were established as annexes in the hospital - and a DS centre for the elderly established by a medical cooperation (IDS). The IDS initially opened as a DC centre, but changed to a DS centre in 2003. Furthermore, a DS centre providing outpatient long-term care for dementia patients ('TDS'), managed by a social welfare corporation, opened in March 2006. A DS centre also providing outpatient preventive long-term care ('NDS'), managed by a social welfare corporation, opened in November 2006. Thus in total there is one DC facility and four DS facilities, and the total capacity in M Town is 40 people for DC and 62 people for DS.

In this study, we analysed only the residents of M Town from the attributes of the elderly obtained by the questionnaire survey. That is, elderly people from neighbouring towns were excluded. Also, there was nobody on the waiting list during the period of study. We therefore believe we were able to capture all the attributes of the elderly coming to the day centres in M Town. Specifically, 203 elderly users of DC and DS were analysed at the end of January 2006, 207 at the end of January 2007, and 217 at the end of January 2008. These numbers translate to $8.23 \%$ to $8.71 \%$ of those aged 65 or older in M Town. This ratio greatly exceeds the national rate of $5.82 \%$ (October, 2006). We believe this is due to the comparatively large number of the elderly coming to DC.

\section{Types of elderly people coming to DS and DC}

\subsection{Summary of attributes of the elderly}

Table 3 shows a summary of attributes of the elderly over a period of three years. There were few elderly people going to TDS and NDS because they opened recently, in 2006. Therefore the range varied greatly, and the data were treated as a reference point. As to our results, first, for MDC the percentage of women was about $65 \%$, for MDS $78 \%$, and for IDS $90 \%$; the percentages of women are particularly high for DS.

Next, the average age increased by one every year for MDS and IDS. By contrast, such a trend was not seen in MDC, which maintained an average age of 84 . The average duration for visits showed an upward trend for MDC, but a downward trend for MDS, and for IDS it dropped and then increased. Finally, the average frequency of use was twice a week for MDC and IDS and once a week for MDS; the values were almost the same during the three-year period.

\subsection{Basic trends in the elderly' attributes}

Next, we describe trends in the attributes of the elderly.

Figure 1 shows the distribution of ADL of the elderly using all facilities during the three-year period. Elderly people with B on the Katz scale were the most numerous during the three-year period. The elderly with $\mathrm{F}$ were also comparatively high in number. In other words, the ADL distribution showed two peaks. Furthermore, the number of elderly with A tended to increase each year. 
Figure 1 Distribution of ADL of the elderly

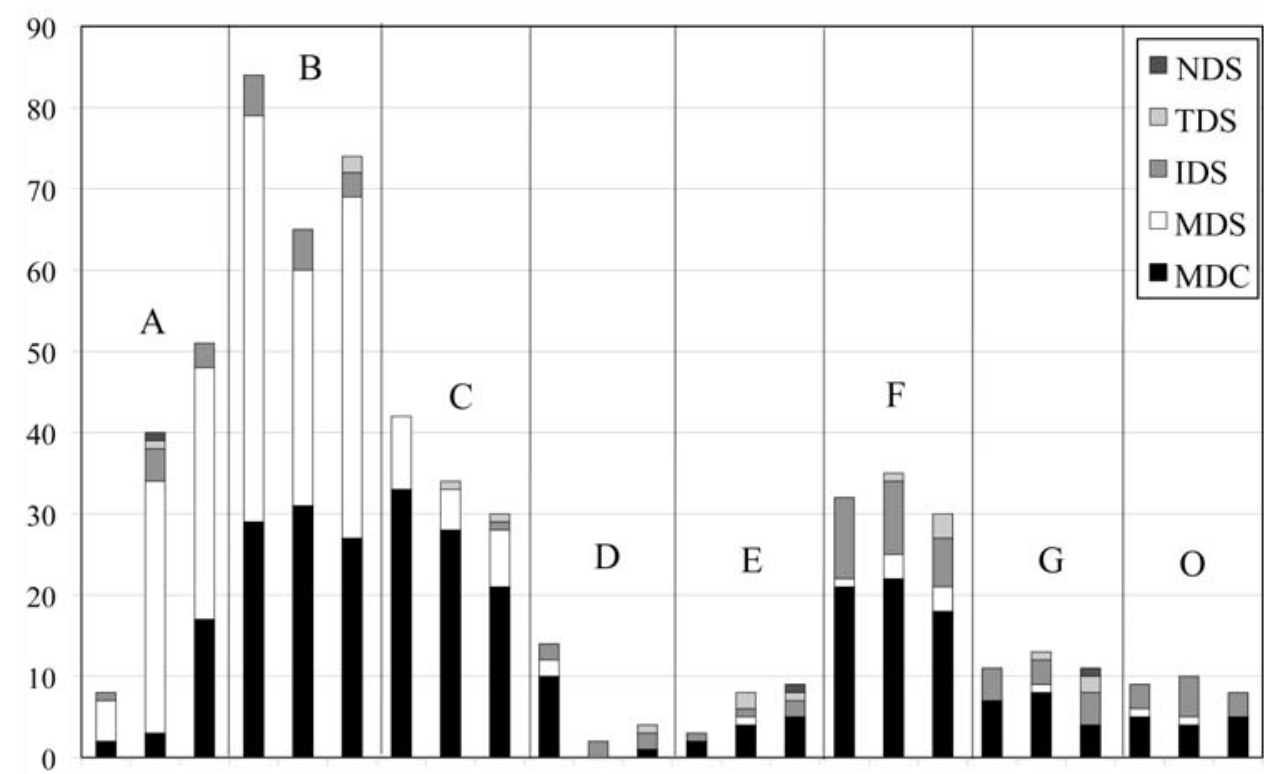

$\begin{array}{llllllllllllllllllllllll}06 & 07 & 08 & 06 & 07 & 08 & 06 & 07 & 08 & 06 & 07 & 08 & 06 & 07 & 08 & 06 & 07 & 08 & 06 & 07 & 08 & 06 & 07 & 08\end{array}$

Figure 2 shows the distribution of dementia. The elderly with either slight or no dementia (I) made up over $50 \%$ of the elderly during the three-year period. However, elderly people with mid-level dementia were also seen. Also seen was a rising trend in the number of elderly with slight dementia (I and IIa).

Figure 2 Distribution of dementia of the elderly

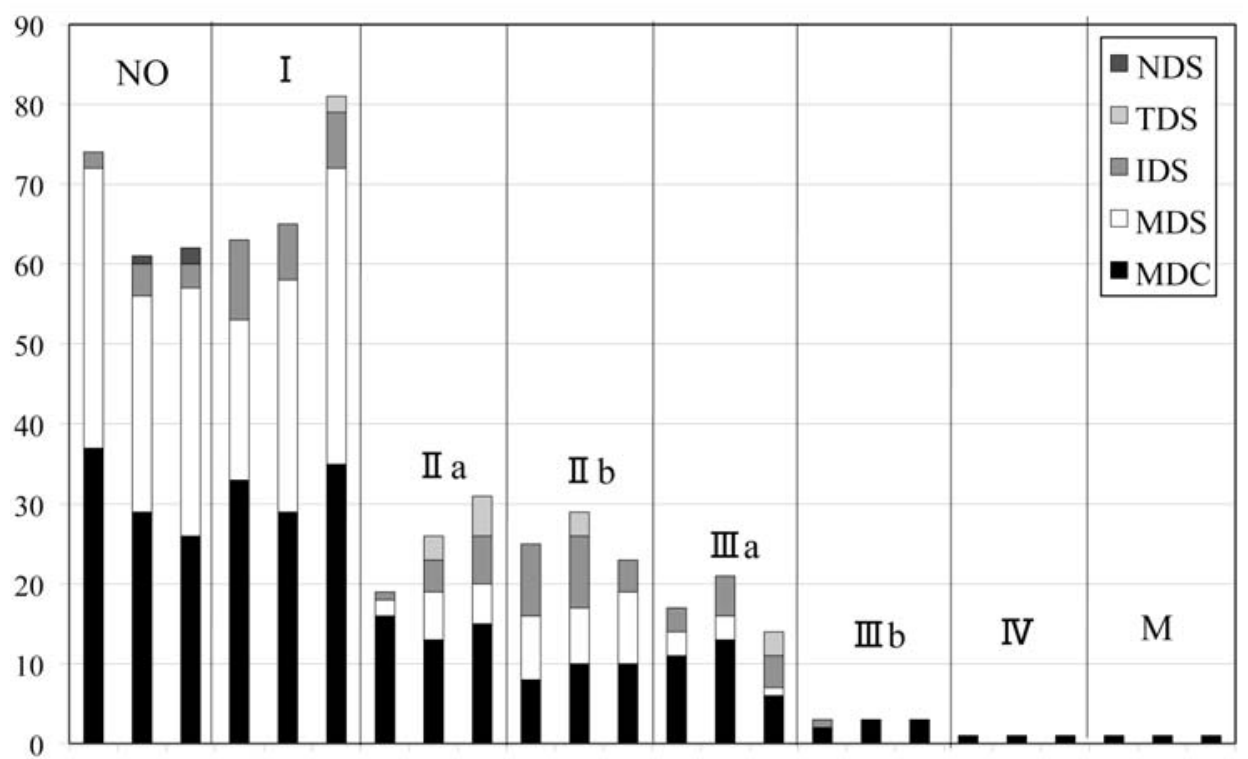

$\begin{array}{llllllllllllllllllllllll}06 & 07 & 08 & 06 & 07 & 08 & 06 & 07 & 08 & 06 & 07 & 08 & 06 & 07 & 08 & 06 & 07 & 08 & 06 & 07 & 08 & 06 & 07 & 08\end{array}$ 
Figure 3 shows the degree of care required. Because Required Support levels 1 and 2 were introduced due to the revision of the Long-Term Care Insurance Act in April 2006, the system of dividing degrees of care required differed between 2006 and the subsequent years. From 2006 to 2007, Required Care 1 decreased, but Required Support 1, Required Support 2, and Required Care 2 rose. Because of this, the distribution of required care tended to be flat. However, the elderly with a low level (Required Care 1 or below) made up over $50 \%$ of the elderly.

Figure 3 Distribution of degree of care required by the elderly

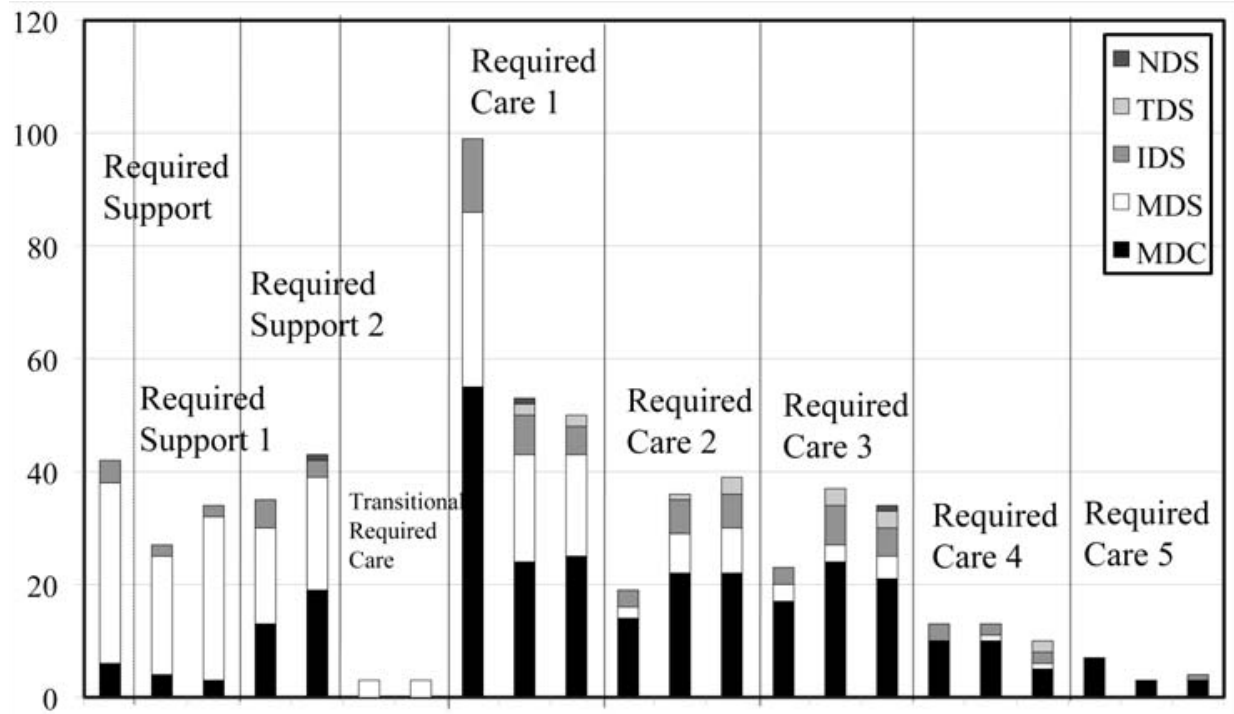

$\begin{array}{llllllllllllllllllllll}06 & 07 & 08 & 07 & 08 & 07 & 08 & 06 & 07 & 08 & 06 & 07 & 08 & 06 & 07 & 08 & 06 & 07 & 08 & 06 & 07 & 08\end{array}$

Figure 4 Distribution of habitation status of elderly

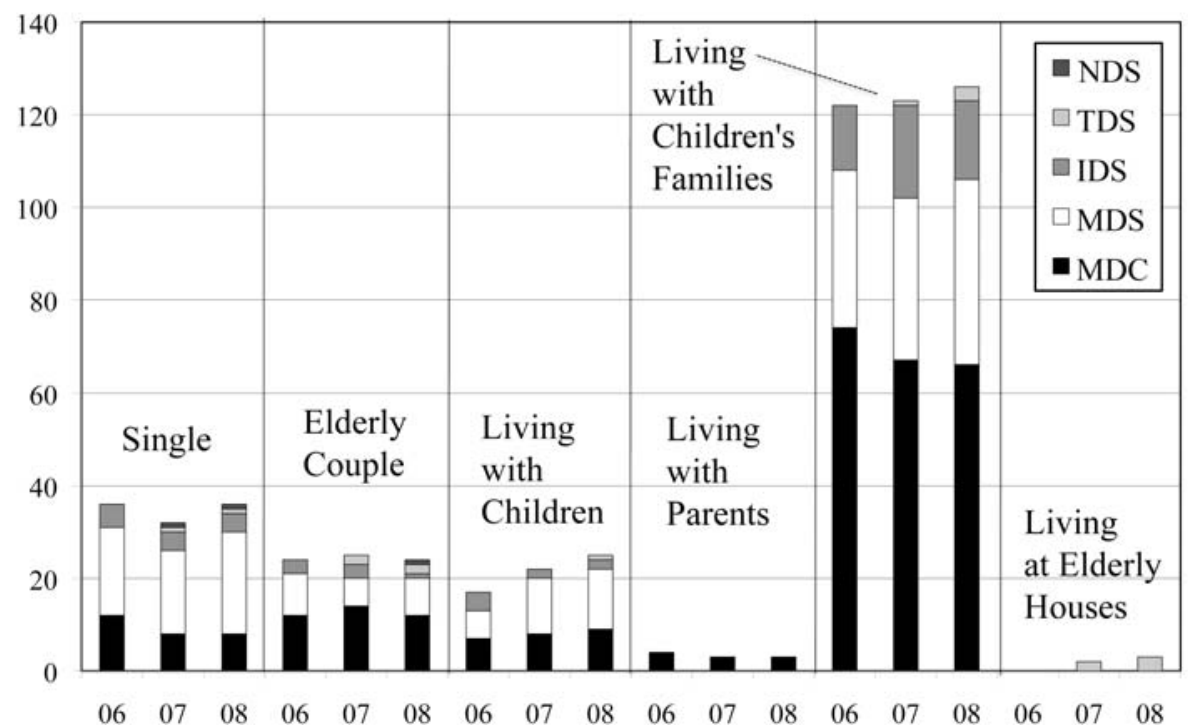


Figure 4 shows habitation statuses. There were few households of singles only or elderly couples only. Over $50 \%$ of the elderly lived with their families. This is same as the general trend in M Town.

\subsection{Typical elderly}

Table 4, Table 5, and Table 6 represent the actual numbers and ratios of the attributes of the elderly as classified by the method described above in 2006, 2007, and 2008, respectively. The elderly who lived alone during the daytime were counted as elderly living alone in the tables. If those who lived alone during the daytime were counted as those living with families, the difference between Types a and b would be 15 people, and 11 people between Types e and $\mathrm{f}$ (see Table 7, 2006). The number of the elderly living alone during the daytime was 68 out of a total of 203 elderly (33.5\%) in 2006, 70 out of $207(33.8 \%)$ in 2007, and 72 out of 217 (33.1\%) in 2008, roughly one-third of all the elderly.

Table 4 Actual numbers and ratios of the attributes of the Elderly' (2006)

\begin{tabular}{|c|c|c|c|c|c|c|c|c|c|}
\hline Type & $M D C$ & $M D S$ & $I D S$ & $T D S$ & $N D S$ & M town & Category $A$ & Category $B$ & Category $C$ \\
\hline $\mathrm{a}$ & 14 & 23 & 1 & 0 & 0 & 38 & $19 \%$ & $37.9 \%$ & $45.3 \%$ \\
\hline $\mathrm{b}$ & 10 & 25 & 4 & 0 & 0 & 39 & $19 \%$ & & \\
\hline $\mathrm{c}$ & 6 & 2 & 0 & 0 & 0 & 8 & $4 \%$ & $7.4 \%$ & \\
\hline $\mathrm{d}$ & 1 & 5 & 1 & 0 & 0 & 7 & $3 \%$ & & \\
\hline $\mathrm{e}$ & 50 & 7 & 5 & 0 & 0 & 62 & $31 \%$ & $38.4 \%$ & $54.7 \%$ \\
\hline $\mathrm{f}$ & 11 & 2 & 3 & 0 & 0 & 16 & $8 \%$ & & \\
\hline g & 15 & 3 & 9 & 0 & 0 & 27 & $13 \%$ & $16.3 \%$ & \\
\hline $\mathrm{h}$ & 2 & 1 & 3 & 0 & 0 & 6 & $3 \%$ & & \\
\hline Total & 109 & 68 & 26 & 0 & 0 & 203 & $100 \%$ & $100 \%$ & $100 \%$ \\
\hline \multicolumn{10}{|l|}{ Notes: } \\
\hline Type & \multicolumn{2}{|c|}{$A D L$} & \multicolumn{3}{|c|}{ Dementia } & \multicolumn{4}{|c|}{ Living status } \\
\hline $\bar{a}$ & \multicolumn{2}{|c|}{$\mathrm{A}, \mathrm{B}$} & \multicolumn{3}{|c|}{ 0, I, IIa } & \multicolumn{4}{|c|}{ Those who lived with their families } \\
\hline $\mathrm{b}$ & \multicolumn{2}{|c|}{$\mathrm{A}, \mathrm{B}$} & \multicolumn{3}{|c|}{ 0, I, IIa } & \multicolumn{4}{|c|}{ Those who lived alone during the daytime } \\
\hline $\mathrm{c}$ & \multicolumn{2}{|c|}{$\mathrm{A}, \mathrm{B}$} & \multicolumn{3}{|c|}{ II b, III, IV, M } & \multicolumn{4}{|c|}{ Those who lived with their families } \\
\hline $\mathrm{d}$ & \multicolumn{2}{|c|}{$\mathrm{A}, \mathrm{B}$} & \multicolumn{3}{|c|}{ II b, III, IV, M } & \multicolumn{4}{|c|}{ Those who lived alone during the daytime } \\
\hline $\mathrm{e}$ & \multicolumn{2}{|c|}{ C, D, E, F, G, O } & \multicolumn{3}{|c|}{0 , I, IIa } & \multicolumn{4}{|c|}{ Those who lived with their families } \\
\hline $\mathrm{f}$ & \multicolumn{2}{|c|}{$C, D, E, F, G, O$} & \multicolumn{3}{|c|}{ 0, I, IIa } & \multicolumn{4}{|c|}{ Those who lived alone during the daytime } \\
\hline $\mathrm{g}$ & \multicolumn{2}{|c|}{$\mathrm{C}, \mathrm{D}, \mathrm{E}, \mathrm{F}, \mathrm{G}, \mathrm{O}$} & \multicolumn{3}{|c|}{ II b, III, IV, M } & \multicolumn{4}{|c|}{ Those who lived with their families } \\
\hline $\mathrm{h}$ & \multicolumn{2}{|c|}{ C, D, E, F, G, O } & \multicolumn{3}{|c|}{ II b, III, IV, M } & \multicolumn{4}{|c|}{ Those who lived alone during the daytime } \\
\hline
\end{tabular}

We will first examine the overall trends. Category $\mathrm{C}$ indicates the ratio of those who needed physical care to those who did not. In 2006, slightly more elderly people needed physical help than did not. However, the trend reversed in 2007, and then strengthened in 2008.

Second, Category B divides the elderly by their severity of dementia. The percentage of the elderly with slight dementia was $76.3 \%$ in $2006,74 \%$ in 2007 , and $81.7 \%$ in 2008 . 
Table 5 Actual numbers and ratios of the attributes of the elderly (2007)

\begin{tabular}{|c|c|c|c|c|c|c|c|c|c|}
\hline Type & $M D C$ & $M D S$ & $I D S$ & $T D S$ & $N D S$ & M Town & Category A & Category B & Category $C$ \\
\hline $\mathrm{a}$ & 13 & 32 & 0 & 1 & 0 & 46 & $22 \%$ & $44.0 \%$ & $51.2 \%$ \\
\hline $\mathrm{b}$ & 12 & 24 & 8 & 0 & 1 & 45 & $22 \%$ & & \\
\hline $\mathrm{c}$ & 8 & 2 & 1 & 0 & 0 & 11 & $5 \%$ & $7.2 \%$ & \\
\hline d & 2 & 2 & 0 & 0 & 0 & 4 & $2 \%$ & & \\
\hline $\mathrm{e}$ & 40 & 4 & 4 & 1 & 0 & 49 & $24 \%$ & $30.0 \%$ & $48.8 \%$ \\
\hline $\mathrm{f}$ & 7 & 2 & 3 & 1 & 0 & 13 & $6 \%$ & & \\
\hline g & 16 & 1 & 11 & 3 & 0 & 31 & $15 \%$ & $18.8 \%$ & \\
\hline $\mathrm{h}$ & 2 & 4 & 2 & 0 & 0 & 8 & $4 \%$ & & \\
\hline Total & 100 & 71 & 29 & 6 & 1 & 207 & $100 \%$ & $100 \%$ & $100 \%$ \\
\hline \multicolumn{10}{|l|}{ Notes: } \\
\hline Type & \multicolumn{3}{|c|}{$A D L$} & \multicolumn{2}{|c|}{ Dementia } & \multicolumn{4}{|c|}{ Living status } \\
\hline $\mathrm{a}$ & \multicolumn{3}{|c|}{ A, B } & \multicolumn{2}{|c|}{0 , I, IIa } & \multicolumn{4}{|c|}{ Those who lived with their families } \\
\hline $\mathrm{b}$ & \multicolumn{3}{|c|}{ A, B } & \multicolumn{2}{|c|}{ 0, I, IIa } & \multicolumn{4}{|c|}{ Those who lived alone during the daytime } \\
\hline $\mathrm{c}$ & \multicolumn{3}{|c|}{ A, B } & \multicolumn{2}{|c|}{ II b, III, IV, M } & \multicolumn{4}{|c|}{ Those who lived with their families } \\
\hline d & \multicolumn{3}{|c|}{ A, B } & \multicolumn{2}{|c|}{ II b, III, IV, M } & \multicolumn{4}{|c|}{ Those who lived alone during the daytime } \\
\hline $\mathrm{e}$ & \multicolumn{3}{|c|}{$\mathrm{C}, \mathrm{D}, \mathrm{E}, \mathrm{F}, \mathrm{G}, \mathrm{O}$} & \multicolumn{2}{|c|}{ 0, I, IIa } & \multicolumn{4}{|c|}{ Those who lived with their families } \\
\hline $\mathrm{f}$ & \multicolumn{3}{|c|}{ C, D, E, F, G, O } & \multicolumn{2}{|c|}{0 , I, IIa } & \multicolumn{4}{|c|}{ Those who lived alone during the daytime } \\
\hline $\mathrm{g}$ & \multicolumn{3}{|c|}{ C, D, E, F, G, O } & \multirow{2}{*}{\multicolumn{2}{|c|}{ II b, III, IV, M }} & \multicolumn{4}{|c|}{ Those who lived with their families } \\
\hline $\mathrm{h}$ & \multicolumn{3}{|c|}{$C, D, E, F, G, O$} & & & \multicolumn{4}{|c|}{ Those who lived alone during the daytime } \\
\hline
\end{tabular}

Table 6 Actual numbers and ratios of the attributes of the elderly (2008)

\begin{tabular}{|c|c|c|c|c|c|c|c|c|c|}
\hline Type & $M D C$ & $M D S$ & $I D S$ & $T D S$ & $N D S$ & M Town & Category A & Category B & Category $C$ \\
\hline $\mathrm{a}$ & 21 & 37 & 0 & 1 & 0 & 59 & $27 \%$ & $48.8 \%$ & $57.1 \%$ \\
\hline $\mathrm{b}$ & 10 & 31 & 6 & 0 & 0 & 47 & $22 \%$ & & \\
\hline $\mathrm{c}$ & 11 & 2 & 0 & 0 & 0 & 13 & $6 \%$ & $8.3 \%$ & \\
\hline $\mathrm{d}$ & 2 & 3 & 0 & 0 & 0 & 5 & $2 \%$ & & \\
\hline $\mathrm{e}$ & 39 & 3 & 6 & 4 & 1 & 53 & $24 \%$ & $32.9 \%$ & $42.9 \%$ \\
\hline $\mathrm{f}$ & 7 & 2 & 4 & 1 & 1 & 15 & $7 \%$ & & \\
\hline $\mathrm{g}$ & 8 & 2 & 6 & 4 & 0 & 20 & $9 \%$ & $12.1 \%$ & \\
\hline $\mathrm{h}$ & 0 & 3 & 2 & 0 & 0 & 5 & $2 \%$ & & \\
\hline Total & 98 & 83 & 24 & 10 & 2 & 217 & $100 \%$ & $100 \%$ & $100 \%$ \\
\hline \multicolumn{10}{|l|}{ Notes: } \\
\hline Type & \multicolumn{3}{|c|}{$A D L$} & \multicolumn{2}{|c|}{ Dementia } & \multicolumn{4}{|c|}{ Living status } \\
\hline $\mathrm{a}$ & \multicolumn{3}{|c|}{$\mathrm{A}, \mathrm{B}$} & \multicolumn{2}{|c|}{0 , I, IIa } & \multicolumn{4}{|c|}{ Those who lived with their families } \\
\hline $\mathrm{b}$ & \multicolumn{3}{|c|}{ A, B } & \multicolumn{2}{|c|}{0 , I, IIa } & \multicolumn{4}{|c|}{ Those who lived alone during the daytime } \\
\hline $\mathrm{c}$ & \multicolumn{3}{|c|}{ A, B } & \multicolumn{2}{|c|}{ II b, III, IV, M } & \multicolumn{4}{|c|}{ Those who lived with their families } \\
\hline $\mathrm{d}$ & \multicolumn{3}{|c|}{ A, B } & \multicolumn{2}{|c|}{ II b, III, IV, M } & \multicolumn{4}{|c|}{ Those who lived alone during the daytime } \\
\hline $\mathrm{e}$ & \multicolumn{3}{|c|}{$\mathrm{C}, \mathrm{D}, \mathrm{E}, \mathrm{F}, \mathrm{G}, \mathrm{O}$} & \multicolumn{2}{|c|}{0 , I, IIa } & \multicolumn{4}{|c|}{ Those who lived with their families } \\
\hline $\mathrm{f}$ & \multicolumn{3}{|c|}{ C, D, E, F, G, O } & \multicolumn{2}{|c|}{ 0, I, IIa } & \multicolumn{4}{|c|}{ Those who lived alone during the daytime } \\
\hline $\mathrm{g}$ & \multicolumn{3}{|c|}{ C, D, E, F, G, O } & \multicolumn{2}{|c|}{ II b, III, IV, M } & \multicolumn{4}{|c|}{ Those who lived with their families } \\
\hline $\mathrm{h}$ & \multicolumn{3}{|c|}{$\mathrm{C}, \mathrm{D}, \mathrm{E}, \mathrm{F}, \mathrm{G}, \mathrm{O}$} & \multicolumn{2}{|c|}{ II b, III, IV, M } & \multicolumn{4}{|c|}{ Those who lived alone during the daytime } \\
\hline
\end{tabular}


The percentage of those with severe dementia was $23.7 \%$ in $2006,26 \%$ in 2007 , and $20.4 \%$ in 2008 . The general picture is that $80 \%$ of the elderly have slight dementia, compared to $20 \%$ with severe dementia.

Next, Category A shows the habitation status of the elderly - whether they live alone during the daytime or with family. The proportions of those living with their families all the time were $67.0 \%$ in $2006,66 \%$ in 2007 , and $66 \%$ in 2008 . The percentages of those who live alone during the daytime were $33.0 \%$ in $2006,34.0 \%$ in 2007 , and $33.0 \%$ in 2008.

For Table 4 to Table 6 , the following three types have an appearance ratio of almost $10 \%$ or greater. They can be considered the primary types of the elderly outpatient facilities.

- (e) Elderly who need physical care but are mentally self-reliant

- (g) Elderly who need physical care and have severe dementia

- (a, b) Elderly who do not need physical care and do not have dementia. (Half of them were living alone during the daytime.)

Alternatively, the types of the elderly coming to the facilities were: the handicapped elderly, elderly with dementia, and elderly who lived alone during the daytime.

Chronologically compared to Ohara's 1989 study (8), these elderly types differ in the following two ways.

1 The elderly with dementia, who in 1989 were included in the category of those with increased needs, have become a definitive type of user today (in Sato et al.'s 1996 study (10), they had already become a main type in their own right).

2 Because Types a and b were seen in large numbers, we must recognise them as groups having needs, regardless of whether or not they lived alone during the day. In this connection, Types a and $\mathrm{b}$ contain the elderly covered by the Outpatient Preventive Long-Term Care Insurance Act, enacted in April 2006. Their attributes are 'required support 1' and 'required support 2', which correspond to 'required support' as it was categorised before the revision of the Long-Term Care Insurance Act in 2006.

Therefore, these three types have been established as user types of outpatient facilities. The types of elderly who use outpatient facilities in M Town are similar to those reported in Japanese nationwide research.

Table 7 Differences between counting approach to those who lived with their families but were alone during the day (2006)

\begin{tabular}{lcccccccc}
\hline Types & $a$ & $b$ & $c$ & $d$ & $e$ & $f$ & $g$ & $h$ \\
\hline $\begin{array}{l}\text { If those who live alone only during the daytime } \\
\text { are counted as those who live with families }\end{array}$ & 53 & 24 & 10 & 5 & 73 & 5 & 30 & 3 \\
$\begin{array}{l}\text { If those who live alone only during the daytime } \\
\text { are counted as those who live alone }\end{array}$ & 38 & 39 & 8 & 7 & 62 & 16 & 27 & 6 \\
\hline
\end{tabular}




\subsection{Characteristics of typical elderly users of each centre}

Figure 5 depicts the change in composition of user types for each centre by year. Due to the fact that the number of the elderly coming to TDS and NDS are few, they were treated as reference points. One can see user trends from Tables 4 to 6 and Figure 5. Elderly who needed physical care but did not have dementia (e) were the largest group of elderly people who went to MDC. For MDS, the largest group consisted of the elderly who did not need physical care and did not have dementia ( $a$ and $b$ ), and for IDS it was the elderly with a high level of dementia ( $g$ and $h$ ). In other words, each facility could be seen performing its role. We believe this is not coincidental. This is because while there are many cases of the elderly who go to DC centres but whose needs could be met at DS centres, in M Town, MDC and MDS are joined in one location, so the elderly are routed to their appropriate facility. Also, IDS, a smaller facility, specialises in serving the elderly with comparatively severe dementia. However, because MDC provides a dementia care programme, in 2006 and 2007 it was used by more elderly with comparatively severe dementia ( $\mathrm{g}$ and $\mathrm{h}$ ). Afterwards, the number of elderly users with severe dementia dropped slightly, and overall those groups ( $g$ and $h$ ) became more numerous at DS.

Figure 5 Change in composition of user types for each centre by year

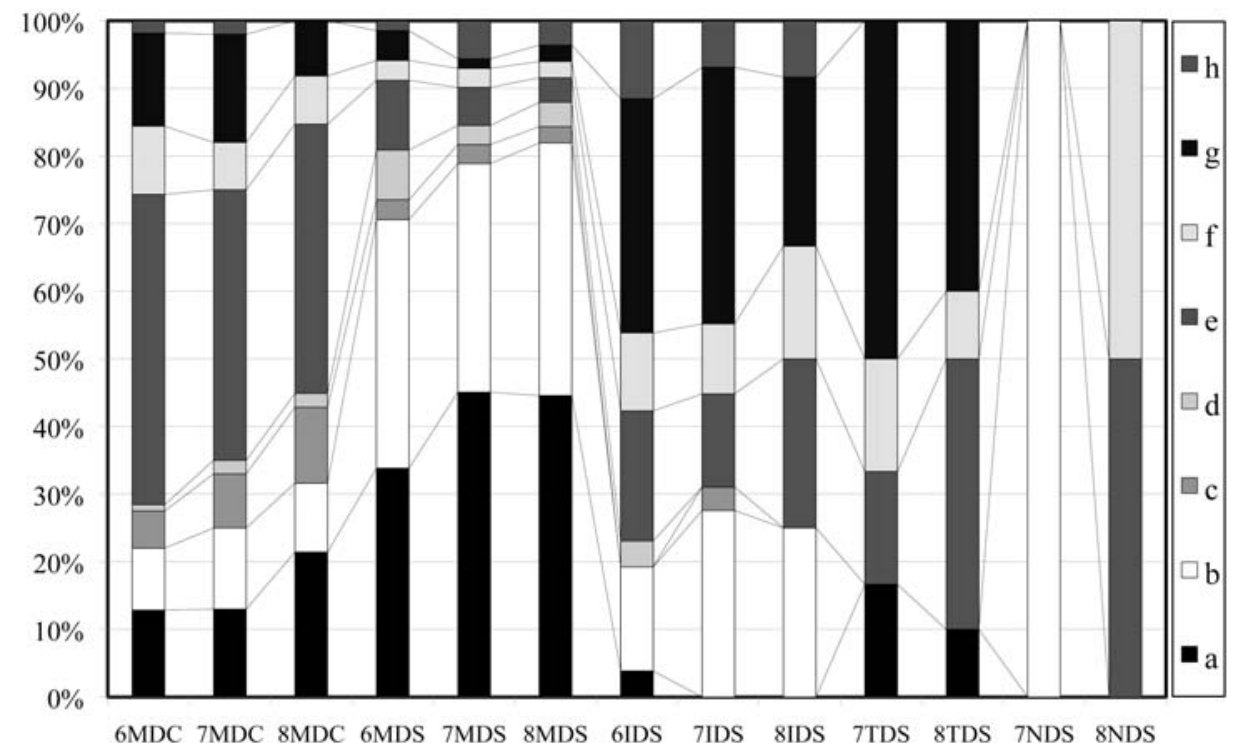

\subsection{Roles of outpatient facilities}

Also refer to definitions of DS and $\mathrm{DC}^{4,5}$. The needs surmised from the types of the elderly coming to the facilities and the roles played by the outpatient facilities can be considered as follows (Figure 6):

a A place for providing substantive services. - Handicapped elderly require the care of others for their needs, with tasks such as moving, eating, evacuating, and bathing, as well as for physical rehabilitation. They have a substantive need for receiving such 
services, which are the most basic services provided by outpatient facilities. This is not expected to change in the future. These days, machine training for preventing such needs arising is also included here.

b A place where the elderly spend the daytime. - The elderly with this need are primarily elderly with dementia and those who live alone during the daytime. In the case of elderly with dementia, their use is due more to the wishes of their families than their own desires. Providing respite care for families caring for the elderly with dementia in their homes has become an important function of outpatient facilities. In the case of the elderly who live alone during the daytime, they need places to stay during the day. Particularly for the elderly who live alone, it is believed that not having a place to stay outside of home can easily lead to lack of social contact.

c Elimination of a sense of social isolation (a place for contact). - For the elderly who live alone during the daytime, it is especially easy to feel a sense of social isolation. This is also true for elderly people with physical disabilities, who have limited opportunities to go out. This sense of isolation may be reduced by sharing time, space, and activities with those of the same generation. Therefore the problem cannot be simply resolved with home services.

Outpatient facilities thus have a meaningful role.

Figure 6 Typical elderly users and roles of outpatient facilities

\begin{tabular}{|l|l|}
\hline \multicolumn{1}{|c|}{ Typical Users } & A Place for Providing \\
\hline The Handicapped Elderly & A Place where the \\
\hline The Elderly with Dementive & Elderly Spend Daytime \\
\hline $\begin{array}{l}\text { The Elderly who Live } \\
\text { Alone during Daytime }\end{array}$ \\
\hline
\end{tabular}

\section{A model of the DC system in $m$ town from the viewpoint of the elderly types and roles of facilities (Figure 7)}

In this section of the paper, we make some observations concerning the system of day centres from the types of the elderly coming to the facilities in M Town and the roles of the centres.

In M Town, the MDC's dementia care centre and IDS gather almost all the local elderly with dementia. Because MDC separates the elderly by purpose - those who seek dementia care and those who seek rehabilitation - it is able to first separate the elderly with dementia and those without.

Second, for the elderly without dementia, because MDS and MDC are located in the same building, the hospital is able to transfer the elderly from DC to DS if rehabilitation 
is not needed. In reality, the services used besides rehabilitation in DC do not differ so much from the services in DS. Moreover, machine training, for preventing the need for care arising in the first place, is provided at MDC. Therefore, it is possible for MDC and MDS combined to be perceived as an integrated DC centre with personal rehabilitation functions. This integrated DC centre has strong connections with medical and healthcare facilities for the elderly.

Therefore, it can be considered an integrated DC centre where rehabilitation is also provided, and several DC centres for the elderly with dementia play each role effectively in M Town.

This model is formed by the conditions of M Town, where care is centred on a public hospital with connections to care facilities.

The system, whereby several small DC centres receive the elderly with dementia and an integrated DC centre (where rehabilitation is also provided) receives the handicapped elderly and elderly who lived alone during the daytime, is reasonable in depopulated and ageing areas which require the effective and efficient provision of care services. Therefore, a care system centred on the public hospital is effective in the area.

Figure 7 Model of DC system in M town

\begin{tabular}{|c|c|c|}
\hline $\begin{array}{l}\text { Typical } \\
\text { Users }\end{array}$ & $\begin{array}{l}\text { The Elderly } \\
\text { with Dementia } \\
\text { g,h }\end{array}$ & $\begin{array}{ll}\text { The } & \text { The Elderly } \\
\text { Hanicappe } & \text { who Live } \\
\text { d Elderly } & \text { Alone during } \\
\text { e } & \text { Daytime } \\
& \text { a,b }\end{array}$ \\
\hline Examples & $\left\{\begin{array}{l}\text { IDS } \\
\text { TDS }\end{array}\right.$ & MDS \\
\hline \multirow{2}{*}{$\begin{array}{l}\text { Providing } \\
\text { Services }\end{array}$} & & Rehabilitation Training \\
\hline & \multicolumn{2}{|c|}{ Pickup, Lunch, and Bathing } \\
\hline \multirow{3}{*}{$\begin{array}{l}\text { The Roles } \\
\text { of } \\
\text { Facilities }\end{array}$} & \multicolumn{2}{|c|}{ A Place for Providing Substantive Service } \\
\hline & A Place where the & Elderly Spend Daytime \\
\hline & & A Place for Contact \\
\hline $\begin{array}{l}\text { The System } \\
\text { of Facilities }\end{array}$ & $\begin{array}{l}\text { Day Care Center } \\
\text { for the Elderly } \\
\text { with Dementia }\end{array}$ & $\begin{array}{l}\text { The Integrated } \\
\text { Day Care Center }\end{array}$ \\
\hline
\end{tabular}

\section{Conclusions}

In this paper the overall picture of users of DSs and DC centres for the elderly has been clarified thorough a case study in a moderately mountainous area, notably where a care system centred on the public hospital has been established, and its change over time. We also discussed the roles and systems of these centres. Our findings are as follow: 
1 There were three types of elderly users: those who needed physical care, those with dementia, and those who lived alone in the daytime.

2 The roles of the DC and DS centres for the elderly were: as places that provide physical care services, as places where the elderly stay during the daytime, and as places where they have social interactions.

3 In M Town, which is a comparatively closed area located in a central mountainous region and where a care system centred on the public M hospital has been established, the system of an integrated DC centre where rehabilitation is also provided and several DC centres for the elderly with dementia play each role effectively in the town.

The DC system in M Town can be applicable especially to the areas where the service areas are strictly partitioned off, because $\mathrm{M}$ Town is also an enclosed area due to geographical reasons. Even more, it may be more applicable in depopulated and ageing areas, because public hospital already plays large part in depopulated and ageing areas (Matsumoto, 2005).

As a significance of the study, in this paper we introduced a combination of indexes of the elderly's physical condition, severity of dementia, and habitation status. We could show the characteristic types of the elderly who come to DC centres and the roles of the DC and DS centres in the case study. On the contrary, previous studies show the elderly's condition by each index only. At present we suppose that these typical types of the elderly who come to the centres and the roles of the centres can be applicable in general, although ratios of composition of each type are different, we need further studies in other areas in another elderly care systems to convince the generality of typical types and the roles of the centres. It may be different even in the countries where there are established family ethics regarding aging parents.

\section{References}

Ara, S. (1997) 'Housing facilities for the elderly in India', Ageing International, Vol. 23, Nos. 3-4, pp.107-114.

Brink, S. (1997) 'The graying of our communities worldwide', Ageing International, Vol. 23, Nos. 3-4, pp.13-31.

Chi, I. and Chow, N. (1997) 'Housing and family care for the elderly in Hong Kong', Ageing International, Vol. 23, Nos. 3-4, pp.65-77.

Chida, N. and Ueno, J. et al. (1996) 'A study on the reorganization and the architectural planning of day facilities for the elderly', Summaries of Technical Papers of Annual Meeting Architectural Institute of Japan. Architectural Planning and Design, E-1, pp.225-226, Architectural Institute of Japan, Tokyo, Japan.

Dummer, T.J.B., Halsall, J.P. and Cook, I.G. (2011) 'Longevity in the 21st century: a global environmental perspective', International Journal of Society Systems Science, Vol. 3, No. 4, pp.325-332.

Egdom, G. (1997) 'Housing for the elderly in the Netherlands: a care problem', Ageing International, Vol. 23, Nos. 3-4, pp.1365-182.

Gottshalk, G. (1999) 'Introduction to: 'housing and care for various groups of elderly people', Independent European Housing Forum Conference: Living Condition for the European Elderly, 25-26 September, Kuopio. 
Harrison, J. (1997) 'Housing for the ageing population of Singapore', Ageing International, Vol. 23, Nos. 3-4, pp.32-48.

Hwang, Y. (1997) 'Housing for the elderly in Taiwan', Ageing International, Vol. 23, Nos. 3-4, pp.133-147.

Japanese Ministry of Health, Labor and Welfare (2006) Revision of 'About Application of Index of Independency in Daily Living of the Elderly with Dementia, Notification by the Ministry, Tokyo, Japan.

Katan, Y. and Werczberger, E. (1997) 'Housing for elderly people in Israel', Ageing International, Vol. 23, Nos. 3-4, pp.49-64.

Katz, S., Down, T.D., Cash, H.R. and Grotz, R.C. (1970) 'Progress in the development of the index of ADL', The Gerontologist, Vol. 10, No. 1, pp.20-30.

Kim, M. (1997) 'Housing policies for the elderly in Korea', Ageing International, Vol. 23, Nos. 3-4, pp.78-89.

Kose, S. (1997) 'Housing elderly people in Japan', Ageing International, Vol. 23, Nos. 3-4, pp.148-164.

Lindstroem, B. (1997) 'Housing and service for the elderly in Denmark', Ageing International, Vol. 23, Nos. 3-4, pp.115-132.

Matsumoto, H. (2005) Report on 'A Study for Establishment of Total Care-System for Preventing the Elderly's Hospitalization and Reduction of Hospitalization Costs, Japan Public Health Association, Tokyo, Japan.

Miyata, K. and Ueno, J. et al. (1996) 'A study on the reorganization and the architectural planning of day facilities for the elderly', Summaries of Technical Papers of Annual Meeting Architectural Institute of Japan. Architectural Planning and Design, Vol. E-1, pp.227-228, Architectural Institute of Japan, Tokyo, Japan.

Nikkei Newspaper (2011) 28th November, Japan.

Nishino, T. (2005) A Study on Architectural Planning of Day Care Centers for the Elderly', from the Point of the Elderly' Behavioral Ways, Unpublished PhD thesis, The University of Tokyo, Tokyo, Japan.

Nishino, T. (2007) 'A case study on collective treatments in Japanese day care centers for the elderly, from the point of activities within a place', Journal of Architecture and Planning, Vol. 72, No. 614, pp.49-55.

Nishino, T. and Nagasawa, Y. (2006) 'Activities and characteristics of space use in senior centers in Aarhus, Denmark', Journal of Architecture and Planning, Vol. 71, No. 601, pp.57-64.

Nosaka, M. and Yoshikawa, T. (1999) 'A study on location-allocation planning of day facilities for the elderly: a case study on estimated future population of Tama New Town', Journal of Architecture, Planning and Environmental Engineering, Vol. 64, No. 525, pp.201-208.

Ohara, K. (1989) Study on Removals of Senior Citizen's Living Places from the point of Architectural Planning, Unpublished PhD thesis, The University of Tokyo, Tokyo, Japan.

Parker, S. and Pant, B. (2011) 'Longevity in Nepal: health, policy and service provision challenges', International Journal of Society Systems Science, Vol. 3, No. 4, pp.333-345.

Saito, J. and Matsumoto, H. (1992) 'Basic study on the architectural planning of day care and day service centers', Summaries of Technical Papers of Annual Meeting Architectural Institute of Japan. Architectural Planning and Design, pp.557-558, Architectural Institute of Japan, Tokyo, Japan.

Sato, Y. and Ueno, J. et al. (1996) 'A study on the reorganization and the architectural planning of day facilities for the elderly', Summaries of Technical Papers of Annual Meeting Architectural Institute of Japan. Architectural Planning and Design, Vol. E-1, pp.213-214, Architectural Institute of Japan, Tokyo, Japan.

Sugawara, M., Aizawa, H. and Aiba, Y. (2004) 'Space arrangement for day service center seen from the elderly activities', Journal of Architecture and Planning, Vol. 69, No. 585, pp.39-45. 
Sugawara, M., Aizawa, H. and Shinozuka, M. (2006) 'Community function and management of aging society in mountainous region: Community planning for aging society Part 1', Journal of Architecture and Planning, Vol. 71, No. 600, pp.81-87.

Tanaka, Y. and Ueno, J. et al. (2002) 'An investigation study on the social day space for the independent elderly people: a case study on the community centers in Tama City', Journal of Architecture, Planning and Environmental Engineering, Vol. 67, No. 562, pp.165-172.

Tobari, E. and Ueno, J. et al. (2001) 'A case study on how to reorganize the community and human relations in the context of the elderly's rural life: Aspects of 'Chien' in the elderly's life', Journal of Architecture, Planning and Environmental Engineering, Vol. 66, No. 540, pp.125-132.

Tobari, E. and Ueno, J. et al. (2002) 'A study on the space structure of the day service center for the elderly from the view point of the elderly's activity', Journal of Architecture, Planning and Environmental Engineering, Vol. 67, No. 556, pp.161-168.

Tsuno, N. and Honma, A. (2009) 'Ageing in Asia - the Japan experience', Ageing International, Vol. 34, Nos. 1-2, pp.1-14.

\section{Notes}

1 Long-term outpatient day care is provided at the day service centres for the elderly ('DS'). Outpatient rehabilitation is also provided at day care centres for the elderly ('DC'). In this study, these two kinds of centres are referred to together as 'the elderly outpatient facilities'.

2 Community comprehensive care is defined as "care that takes into account social factors while seeking to continually improve the quality of life of residents by providing not only care and cure, but also all aspects of health services (building health), home care, rehabilitation, welfare, and nursing services. It is holistic care that includes a vision of life and normalization with the participation of residents and partnership between facility care and home care". Source: M public hospital home page.

3 The number of households occupied by a single elderly resident is calculated based on the number of interviewees. It is lower than the actual number of such households. Japanese nationwide data is taken from the websites of the Ministry of Internal Affairs and Communications and the Ministry of Health, Labor and Welfare. Data on the number of households of the elderly living alone nationwide is available only as of October 2005.

4 "Day service centers for the elderly, applicable as Designated In-Home Services, are facilities whose purpose must be to provide services so that the elderly, even if in the condition of requiring care, can live their daily lives autonomously in their homes to the best of their abilities, based on the capabilities they possess. Centers provide care necessary for daily life and functional training to reduce elderly people's feelings of isolation, maintain the capabilities of their bodies and minds, and lighten the physical and psychological burden of their families". Source: "Standards Concerning Personnel, Facilities, and Operation of Designated In-Home Services", Ministry of Health, Labor, and Welfare Ordinance No. 37, Section 92.

5 "Outpatient rehabilitation centers applicable as Designated In-Home Services are facilities whose purpose must be to provide services so that the elderly, even if in the condition of requiring care, can live their daily lives autonomously in their homes to the best of their abilities, based on the capabilities they possess. Centers provide necessary rehabilitation, such as physical therapy and occupational therapy, to maintain or recover the capabilities of elderly people's bodies and minds". Source: Ibid., Section 110. 